\title{
Differences in Veterans' and Nonveterans' End-of-Life Preferences: A Pilot Study
}

\author{
SONIA A. DUFFY, Ph.D., R.N., ${ }^{1,2}$ DAVID RONIS, Ph.D., ${ }^{1,3}$ KAREN FOWLER, M.P.H., ${ }^{1}$ \\ STEPHANIE MYERS SCHIM, Ph.D., R.N., ${ }^{4}$ and FRANCES C. JACKSON, Ph.D., R.N. ${ }^{5}$
}

\begin{abstract}
Background: Investigators conducting focus groups on end-of-life preferences noted that veterans voiced opinions that strongly differed from those of nonveterans.

Objective: The objective of this study was to further explore differences between veterans' and nonveterans' end-of-life preferences.

Methods: Ten focus groups and a pilot survey were conducted.

Setting and sample: The focus groups consisted of Arab Muslims, Arab Christians, Hispanics, blacks, and whites stratified by gender $(n=73)$. Fifteen male veterans were included across all five racial groups.

Measures: A moderator discussion guide was used to lead the focus groups and a pilot survey asked about demographic information and end-of-life preferences.

Results: Veterans were more likely to be married $(p<0.05)$ and less connected to their cultural group $(p<0.05)$ than nonveterans. The focus group results indicated that veterans in this study were more likely to oppose the use of heroic measures compared to nonveterans. More so than nonveterans, veterans felt that their doctors should be frank and open $(p<0.05)$ were strongly in favor of do-not-resuscitate (DNR) orders $(p<0.10)$, yet were less likely to have a proxy $(p<0.10)$ or durable power of attorney $p<0.01)$. Comparing end-of-life preferences, veterans felt less strongly than nonveterans about remembering personal accomplishments $(p<0.05)$, being listened to $(p<0.05)$, being with friends $(p<0.01)$, or being comfortable with their nurse $(p<0.05)$, but did want to be around their pets at the end of life $p<0.10)$.

Implications: The Department of Veterans Affairs is in a unique position to improve endof-life care for veterans. Providing end-of-life care that is congruent with the veteran's wishes can improve satisfaction and increase cost effectiveness by eliminating unacceptable services.
\end{abstract}

\section{INTRODUCTION}

$\mathbf{V}$ ETERANS OF THE U.S. ARMED Forces, who represent approximately $13 \%$ of the population, ${ }^{1}$ account for approximately $28 \%$ of Ameri- can deaths. ${ }^{2}$ Approximately 1800 of the approximately 25 million veterans die daily (approximately 675,000 per year) and the number is increasing every year. ${ }^{3}$ Approximately $15 \%$ of veterans enroll in health care services with the

${ }^{1}$ VA HSR\&D Center for Practice Management and Outcomes Research, VA Ann Arbor Healthcare System, Ann Arbor, Michigan.

${ }^{2}$ Departments of Otolaryngology and Psychiatry, University of Michigan Medical School, Ann Arbor, Michigan.

${ }^{3}$ School of Nursing, University of Michigan, Ann Arbor, Michigan.

${ }^{4}$ College of Nursing, Wayne State University, Detroit, Michigan.

${ }^{5}$ School of Nursing, Oakland University, Rochester, Michigan. 
Veterans Health Administration (VA). ${ }^{4}$ Of those who enroll for VA health care services, $79 \%$ die outside of VA facilities and little is known about the circumstances of their death. Of the $21 \%$ who die within VA settings, $64 \%$ die in acute care settings and $34 \%$ die in extended care settings including hospice. ${ }^{2}$

Of veterans, $37 \%$ are over age 65 compared to $13 \%$ of the general population. ${ }^{3,5}$ Age has been found to be associated with end-of-life preferences. ${ }^{6-8}$ End-of-life preferences have been reported to vary with gender, $6,7,9,10$ and while the number of women in the military is increasing, the majority of veterans (94\%) are male. ${ }^{7,11}$ Approximately $16 \%$ of all veterans are minorities and minority veterans are more likely to use the VA for care than whites. ${ }^{12}$ Many terminally ill veterans treated at VA hospitals are of lower socioeconomic status (SES) (with the median annual income of enrolled veterans that die being $\$ 10,000$ and $25 \%$ having no income). ${ }^{2}$ Approximately $65 \%$ of veteran inpatients who die are not married $^{2}$ and many have poor support systems that can result in psychological distress, ${ }^{13}$ depression, ${ }^{14-19}$ and hospitalization. ${ }^{20}$ It has been speculated that exposure to combat-related life-threatening situations may influence veterans' end-of-life preferences. $^{21}$

Veterans in general are more likely than the U.S. population to be older, males, and have experienced combat exposure that may be associated with end-of-life preferences. ${ }^{6-10,21}$ Yet no studies have been reported that have compared the distinct end-of-life preferences of veterans to those of nonveterans. This pilot study used both focus group and survey methodology to compare selected end-of-life preferences of veterans to nonveterans.

\section{METHODS}

This investigation was part of a study designed to compare end-of-life preferences among different racial/ethnic/cultural groups. Ten, 2-hour long focus groups stratified by race/ethnicity and gender were conducted. The participants were also asked to pretest an end-of-life survey. During the conduct of the focus groups, it became apparent that the veterans had unique opinions about end-of-life care. Hence, further analyses were conducted to understand the end-of-life preferences of veterans. Institutional Review
Board approval was obtained from the University of Michigan and the VA Ann Arbor Healthcare System.

\section{Sample and setting}

A professional marketing firm recruited participants and conducted the focus groups, which were observed by the research team. Inclusion criteria were residents of Southeastern Michigan who: (1) screened positive on the focus group "screener" (short survey) for one of the targeted racial/ethnic/cultural groups (Arab Muslims, Arab Christians, Hispanic/Latinos, blacks, and whites); (2) were over 49 years old; (3) were English speaking; and (4) had no obvious unstable psychiatric signs or symptoms (e.g., confused as to person, place or time, ongoing hallucinations, etc.). The focus group screener was used to recruit a purposive (nonprobability) sample characterized by a variety of factors that may influence end-of-life preferences including information on educational level, religion, and previous experiences with death and dying. "Professional respondents" who may lead or monopolize the discussion were excluded if they had participated in a focus group within the last year. These are standard recruitment procedures for focus groups. $^{22,23}$

\section{Procedures}

Using a moderator discussion guide (outline), the facilitator presented for discussion in the following order: (1) slides; (2) trade-off scenarios; (3) a concept sorting exercise; and (4) issues of discrimination/prejudice. Some examples of the slides used included images of someone on a respirator, clergy visiting a patient, and a picture of Dr. Kevorkian. For those concepts that could not be effectively communicated by pictures, verbal scenarios of end-of-life situations were presented. For example, one of the verbal trade-off scenarios used was:

You are experiencing extreme pain, but when you take pain medication you are no longer alert. Would you rather take pain medication and be pain free even if it meant sleeping most of the time?

Next, participants were asked to participate in a card-sort exercise. For this exercise, 38 end-oflife concepts derived from the literature were 
placed on index cards (e.g., physician communication, not being a burden, avoiding nursing home). The moderator read each concept out loud to the group and asked participants, based on their personal opinions, to sort each card into one of four "hats" that classified the concept as: very important; important; no consensus; and not important. If the group had mixed opinions, the concept was placed in the no-consensus hat. Very important and important concepts were grouped together. Sorting the concepts into hats stimulated the respondents to discuss end-of-life concepts. Because a primary purpose of focus groups is to generate concepts that might be missed by researchers, ${ }^{24}$ with each successive focus group, new concepts (11) that emerged were added to the pile of cards. After the concept sorting exercise, participants were asked to discuss any discrimination/prejudice that they have experienced related to end-of-life care.

The take-home questionnaire asked about demographic information and end-of-life issues. Participants self identified their ethnicity and race using the U.S. Census Bureau two-tiered question and cultural affiliation was measured on a fivepoint scale by asking respondents previously tested questions about connectedness to their cultural group. End-of-life questions were derived from the literature, end-of-life trade-off scenarios, and previously used questionnaires. ${ }^{21,25}$ The survey results served as participant verification (validity) of the focus group results. ${ }^{26}$

\section{Data analysis}

The NUD•IST ${ }^{\mathrm{TM}}$ software program (Scolari/ Sage Publications Software, Newbury Park, CA) was used for the qualitative analysis. The focus group tapes were transcribed and coded by an independent reviewer from the focus group firm. Three researchers independently reviewed the transcripts and identified themes. The researchers compared their findings and identified themes common to each group. The themes from each group were compared and contrasted on a spread sheet. Quantitative data analyses of the pretest surveys were conducted using the SAS statistical program (SAS Institute Inc., Cary, NC). Univariate and bivariate analyses were conducted on the survey results to determine differences between groups using means, frequencies, $\chi^{2}$, and Fisher's exact tests. Because the sample size was small and the survey was a pretest, re- sults were given for significant differences $p<$ 0.10 . Using triangulation, comparisons were made between the concepts and themes identified in the focus group discussions and survey.

\section{RESULTS}

There were 73 focus group participants across the 10 groups ranging from 4 to 9 participants per group. The mean age of the focus group participants was 67 (standard deviation [SD] 8.5; range, 50-83 years). Of the 73 focus group participants, 62 completed and returned the pilot survey (by mail) for a return rate of $85 \%$. There were 28 males and 34 females who returned surveys. Of the 5 racial/ethnic/cultural groups, there were $5 \mathrm{Arab}$ Muslims, 14 Arab Christians, 14 Hispanic/Latinos, 14 blacks, and 15 whites. Most (87\%) of the participants were married. Only $21 \%$ had a high school education or less, while the rest had some college. Most (64\%) were Catholic, 29\% were Protestant, and $7 \%$ were Muslim.

Of those who returned surveys, $24 \%(n=15)$ were veterans. The veterans ranged across all the racial/ethnic/cultural groups (1 Arab Muslim, 3 Arab Christians, 1 Hispanic, 5 blacks, and 5 whites). Three of the veterans served in World War II only, 5 served during Korea only, 5 served during Viet Nam only, 1 served in World War II, Korea, and Viet Nam, and 1 served during preViet Nam peace time (1958-1960). Compared to nonveterans, veterans were more likely to be married $(p<0.05)$, and less likely to be connected to their cultural group $(p<0.05)$, be bilingual $(p<0.10)$, and celebrate cultural holidays $(p<$ $0.10)$. There were no significant differences between veterans and nonveterans on questions related to age, educational status, religion, and spirituality.

Four veterans had been involved in active combat and two noted on the survey that this experience changed their end-of-life preferences. Some comments from veterans during the focus groups follow:

... sometimes in situations with war, Korea, WWII, Vietnam, I've talked with people ... [who have] seen their friends and loved ones in situations where there's no hope. And they have asked, please help me. I'm hurt. I know some have religions that are very strong against it [assisted suicide], but 
we are not our maker. We try to be like him, but we fall short.

I retired from the military. And everyone that I saw that was wounded . . . in the heat of the fight, you see a guy gut shot, he'll holler, I don't want to die. Everyone that I've seen and had to help or assist in some way, I don't want to die, I don't want to die. All we can do is pray for him and introduce him to the Lord in his condition, like he wasn't going to live no way.

I go along with what they're saying about God has the right and he's the only one who should have that decision, but I also disagree because God is here in a sense but he's not here in another sense. We have to decide sometimes what we want for ourselves or for our loved ones or whatever. And we have to hope that it meets with God's approval. If it doesn't then we'll hear about it later.

Survey results indicated differences in end-oflife preferences between veterans and nonveterans. Compared to nonveterans, veterans were in favor of do-not-resuscitate (DNR) orders $(p<$ $0.10)$. However, veterans were less likely than nonveterans to have a proxy $(p<0.10)$ or a durable power of attorney $(p<0.01)$. Veterans felt more strongly than nonveterans that their doctors should be frank and open $(p<0.05)$. More so than nonveterans, veterans did not feel strongly about being with friends $(p<0.01)$, being listened to $(p<0.05)$, remembering personal accomplishments $(p<0.05)$, or feeling comfortable with their nurse $(p<0.05)$, but did want to be around their pets at the end of life $(p<0.10)$. There were no significant differences between veterans and nonveterans related to specific treatment preferences, dying at home versus other settings, assisted suicide, making end-of-life decisions, and facing threatening illnesses (Table 1).

\section{DISCUSSION}

Because veterans may have experience with end-of-life issues (such as combat exposure), it is not surprising that we found distinct preferences related to not wanting heroic measures to prolong life. However, the veterans in this study were less likely than others to have measures in place to carry out their wishes. While the reasons for this are unclear, persons not having advanced directives have been shown to prefer relying on family members or lack knowledge about filling out advance directives. ${ }^{27}$ Encouraging veterans to talk with their families and/or significant others and exploring advance directives and durable powers of attorney should be done while the veteran is still cognizant enough to understand options. Similar to another study, ${ }^{28}$ the veterans in this study felt that communicating with one's physician and preparation for death were important. Open communication with physicians should be encouraged including treatment options, side effects, pain control, and quality of life.

The veterans in this study were less likely than nonveterans to prefer to share time with friends, prefer to be listened to, prefer to remember personal accomplishments, or prefer to be comfortable with their nurse than were nonveterans and may be more socially isolated than nonveterans. Moreover, the veterans in this study were less connected to their cultural group and less likely to be bilingual, suggesting that they are more acculturated (assimilated into mainstream American culture) than others. For veterans, having pets available may be a great source of comfort for those who have experienced combat exposure and feel disconnected from their culture. Veterans may identify closely with their military experience. "Veteran identity" is defined as a selfconcept derived from military service and is strongly associated with black and Hispanic/ Latino ethnicity. ${ }^{12}$

While the veterans in this study did not differ from nonveterans in relation to treatment preferences or dying in the hospital versus home, hospital intensive care unit deaths in the VA in 2001 were $35 \%$ compared to $17 \%$ among Medicare participants. ${ }^{2}$ The VA has made considerable efforts to improve end-of-life care for veterans. Nationwide, nearly two thirds of inpatient veterans deemed appropriate for advanced care planning have discussed preferences with their clinician. ${ }^{29}$ Hospice services are now a guaranteed benefit and educating veterans about hospice may increase access to these services.

\section{Limitations of the study}

The major limitation of this pilot study was the small sample size and purposive sample, which was the trade-off for the rich content received 
Table 1. Significant Bivariate Differences between Veterans' and Nonveterans' End-of-Life Preferences

\begin{tabular}{|c|c|c|c|c|c|}
\hline & \multicolumn{2}{|c|}{$\begin{array}{c}\text { Veteran } \\
(\mathrm{n}=15)\end{array}$} & \multicolumn{2}{|c|}{$\begin{array}{l}\text { Nonveteran } \\
(\mathrm{n}=47)\end{array}$} & \multirow[b]{2}{*}{$\mathrm{p}$ value ${ }^{\mathrm{a}}$} \\
\hline & $\mathrm{n}$ & $\%$ & $\mathrm{n}$ & $\%$ & \\
\hline \multicolumn{6}{|l|}{ Married } \\
\hline Yes & 13 & $87 \%$ & 23 & $50 \%$ & \\
\hline No & 2 & $13 \%$ & 23 & $50 \%$ & 0.0122 \\
\hline \multicolumn{6}{|l|}{ Connected to a cultural group } \\
\hline Very & 2 & $13 \%$ & 20 & $44 \%$ & \\
\hline Somewhat-not at all & 13 & $87 \%$ & 25 & $56 \%$ & 0.0304 \\
\hline \multicolumn{6}{|l|}{ Speak multiple languages } \\
\hline Yes & 5 & $36 \%$ & 29 & $63 \%$ & \\
\hline No & 9 & $64 \%$ & 17 & $37 \%$ & 0.0708 \\
\hline \multicolumn{6}{|l|}{ Celebrate cultural holidays } \\
\hline Often/Always & 5 & $33 \%$ & 27 & $59 \%$ & \\
\hline Never/rarely/sometimes & 10 & $67 \%$ & 19 & $41 \%$ & 0.0876 \\
\hline \multicolumn{6}{|l|}{ Prefer no resuscitation } \\
\hline Strongly agree & 10 & $67 \%$ & 18 & $38 \%$ & \\
\hline Agree-strongly disagree & 5 & $33 \%$ & 29 & $62 \%$ & 0.0546 \\
\hline \multicolumn{6}{|l|}{ Selected a proxy } \\
\hline Yes & 6 & $40 \%$ & 29 & $67 \%$ & \\
\hline No & 9 & $60 \%$ & 14 & $33 \%$ & 0.0614 \\
\hline \multicolumn{6}{|c|}{ Have a durable power of attorney } \\
\hline Yes & 1 & $7 \%$ & 21 & $51 \%$ & \\
\hline No & 14 & $93 \%$ & 20 & $49 \%$ & 0.0025 \\
\hline \multicolumn{6}{|c|}{ Doctor should be frank and open } \\
\hline Strongly agree & 12 & $86 \%$ & 26 & $55 \%$ & \\
\hline Agree-strongly disagree & 2 & $14 \%$ & 21 & $45 \%$ & 0.0394 \\
\hline \multicolumn{6}{|c|}{ Prefer to share time with friends } \\
\hline Strongly agree & 1 & $7 \%$ & 20 & $43 \%$ & \\
\hline Agree-strongly disagree & 14 & $93 \%$ & 26 & $57 \%$ & 0.0092 \\
\hline \multicolumn{6}{|l|}{ Prefer to be listened to } \\
\hline Strongly agree & 2 & $13 \%$ & 21 & $45 \%$ & \\
\hline Agree-strongly disagree & 13 & $87 \%$ & 26 & $55 \%$ & 0.0287 \\
\hline \multicolumn{6}{|c|}{ Prefer to remember personal accomplishments } \\
\hline Strongly agree & 0 & $0 \%$ & 13 & $28 \%$ & \\
\hline Agree-strongly disagree & 14 & $100 \%$ & 34 & $72 \%$ & $0.0278^{\mathrm{b}}$ \\
\hline \multicolumn{6}{|c|}{ Prefer to be comfortable with nurse } \\
\hline Strongly agree & 2 & $13 \%$ & 20 & $43 \%$ & \\
\hline Agree-strongly disagree & 13 & $87 \%$ & 27 & $57 \%$ & 0.0395 \\
\hline \multicolumn{6}{|l|}{ Prefer to be with pets } \\
\hline Neutral/agree & 11 & $73 \%$ & 20 & $47 \%$ & \\
\hline Disagree & 4 & $27 \%$ & 23 & $53 \%$ & 0.0729 \\
\hline
\end{tabular}

${ }^{\mathrm{a}} \chi^{2}$ Test, unless otherwise specified.

'Fisher's exact test.

Note: The sample was small and therefore results are not generalizable to the general population. Moreover, individuals may vary markedly within groups, so it cannot be assumed that every person within a particular group will prefer the care that is generally preferred by their self-identified group.

from the focus groups. A larger, randomized study planned in the future would provide information that is more generalizable and allow for multivariate analyses. Because it was crosssectional, this study did not look at changes in end-of-life preferences over time. While the majority of veterans are male, the lack of female veterans in this study may cause a gender bias. The focus group facilitators were white, which may have limited conversation in some groups. Because minorities were oversampled, they were overrepresented, which is both a strength and weakness of the study. Caution should be taken not to generalize and stereotype veterans recognizing that individual preferences supersede group norms. 


\section{CONCLUSION}

Using both qualitative and quantitative methods, this pilot study compared the end-of-life preferences of veterans and nonveterans. Veterans were found to have distinct end-of-life preferences related to use of heroic measures, physician communication, DNR orders, use of a proxy decision-maker or durable power of attorney, remembering personal accomplishments, being listened to, being with friends, being comfortable with their nurse, and being around their pets at the end of life. The VA is in a unique position to provide end-of-life care that is congruent with the veteran's wishes. Providing end-of-life care in accordance with veterans wishes may improve patient/family satisfaction. Moreover, eliminating unacceptable services may increase cost effectiveness.

\section{ACKNOWLEDGMENTS}

This research was jointly funded by the Michigan Department of Community Health, Blue Cross/Blue Shield of Michigan Foundation (774.11), and the Department of Veterans Affairs. The authors would like to thank the staff of Market Strategies, Inc., including Fred Manske, Carolyn Holmes, and Kourtney Hill for their assistance in conducting the focus groups. Finally, the authors would like to thank the focus group participants who participated in this study for their time and cooperation.

\section{REFERENCES}

1. Mooney C, Zwanziger J, Phibbs CS, Schmitt S: Is travel distance a barrier to veterans' use of VA hospitals for medical surgical care? Soc Sci Med 2000;50: 1743-1755.

2. Principi AJ, Tobin D, Breckenridge J, Kussman M: Creating \& Expanding Hospice \& Palliative Care Programs in VA. April 16, 2002. 〈www.va.gov/oaa/flp/〉 (Last accessed November, 2004).

3. Department of Veterans Affairs: VetPop2001Adj State and National Tables. 〈www.va.gov/vetdata/demographics/VP2001adjsn.htm $\rangle$ (Last accessed December 10, 2004).

4. Department of Veterans Affairs Hospice and Palliative Care Initiative (VAHPC): The hospice-veteran partnership toolkit. 〈www.mywhatever.com/ cifwriter/library/77/5846.html $\rangle$ (Last accessed November, 2004).
5. US Census Bureau: Census 2000 Summary File 1. April 1, 2000. 〈www.factfinder.census.gov/servlet/ DatasetMainPageServlet?_lang = en $)$ (Last accessed December 10, 2004).

6. Johnson MF, Lin M, Mangalik S, Murphy DJ, Kramer AM: Patients' perceptions of physicians' recommendations for comfort care differ by patient age and gender. J Gen Intern Med 2000;15:248-255.

7. Wenger NS, Pearson ML, Desmond KA, Harrison ER, Rubenstein LV, Rogers WH, Kahn KL: Epidemiology of do-not-resuscitate orders. Disparity by age, diagnosis, gender, race, and functional impairment. Arch Intern Med 1995;155:2056-2062.

8. Hamel MB, Lynn J, Teno JM, Covinsky KE, Wu AW, Galanos A, Desbiens NA, Phillips RS: Age-related differences in care preferences, treatment decisions, and clinical outcomes of seriously ill hospitalized adults: Lessons from SUPPORT. I Am Geriatr Soc 2000;48: S176-182.

9. Bookwala J, Coppola KM, Fagerlin A, Ditto PH, Danks JH, Smucker WD: Gender differences in older adults' preferences for life-sustaining medical treatments and end-of-life values. Death Stud 2001;25:127149.

10. Carmel S, Mutran E: Preferences for different life-sustaining treatments among elderly persons in Israel. I Gerontol B Psychol Sci Soc Sci 1997;52:S97-102.

11. Department of Veterans Affairs: VetPop 2001, Table 5L: veterans by race/ethnicity, 1990-2030. 2001. 〈www.va.gov/vetdata/demographics/vetpop2001/data/ 5L.xls (Last accessed November 2004).

12. Harada ND, Damron-Rodriguez J, Villa VM, Washington DL, Dhanani S, Shon H, Chattopadhyay M, Fishbein H, Lee M, Makinodan T, Andersen R: Veteran identity and race/ethnicity: Influences on VA outpatient care utilization. Med Care 2002;40:I117128.

13. Paykel ES: Life events, social support and depression. Acta Psychiatr Scand Suppl 1994;377:50-58.

14. Dennis CL, Hodnett E, Gallop R, Chalmers B: The effect of peer support on breast-feeding duration among primiparous women: A randomized controlled trial. CMAJ 2002;166:21-28.

15. Karter AJ, Ackerson LM, Darbinian JA, D'Agostino RB Jr, Ferrara A, Liu J, Selby JV: Self-monitoring of blood glucose levels and glycemic control: The Northern California Kaiser Permanente Diabetes registry. Am J Med 2001;111:1-9.

16. Schwedes U, Siebolds M, Mertes G: Meal-related structured self-monitoring of blood glucose: Effect on diabetes control in non-insulin-treated type 2 diabetic patients. Diabetes Care 2002;25:1928-1932.

17. Morris PL, Robinson RG, Raphael B, Bishop D: The relationship between the perception of social support and post-stroke depression in hospitalized patients. Psychiatry 1991;54:306-316.

18. Duer S, Schwenk TL, Coyne JC: Medical and psychosocial correlates of self-reported depressive symptoms in family practice. J Fam Pract 1988;27: 609-614. 
19. Brown GW, Andrews B, Harris T, Adler Z, Bridge L: Social support, self-esteem and depression. Psychol Med 1986;16:813-831.

20. Mistry R, Rosansky J, McGuire J, McDermott C, Jarvik L: Social isolation predicts re-hospitalization in a group of older American veterans enrolled in the UPBEAT Program. Unified Psychogeriatric Biopsychosocial Evaluation and Treatment. Int J Geriatr Psychiatry 2001;16:950-959.

21. Blackhall L, Murphy S, Frank G, Michel V, Azen S. Ethnicity and attitudes toward patient autonomy. JAMA 1995;274:820-825.

22. Morgan DL: The Focus Group Guidebook: Focus Group Kit 1. Thousand Oaks, CA: SAGE Publications Inc., 1998.

23. Krueger RA: Developing Questions for Focus Groups: Focus Group Kit 3. Thousand Oaks, CA: SAGE Publications Inc., 1998.

24. Office of Communications National Cancer Institute: Pink Book-Making Health Communication Programs Work. Bethesda, MD: National Institutes of Health, 1992.

25. Tulsky JA: Understanding what is Important at the end of life. 2000. 〈www.hsrd.durham.med.va.gov/ palliative/downloads/finalsurveypatients.doc) (Last accessed March 2001).
26. Krueger RA: Analyzing E Reporting Focus Group Results: Focus Group Kit 6. Thousand Oaks, CA: SAGE Publications Inc., 1998.

27. High DM: Advance directives and the elderly: A study of intervention strategies to increase use. Gerontologist 1993;33:342-349.

28. Steinhauser KE, Clipp EC, McNeilly M, Christakis NA, McIntyre LM, Tulsky JA. In search of a good death: Observations of patients, families, and providers. Ann Intern Med 2000;132(:825-832.

29. Last Acts. Transforming Death in America. Washington DC: Partnership for Caring, Inc., 2002.

Address reprint requests to: Sonia A. Duffy, Ph.D., R.N. Department of Veterans Affairs VA HSRED Center for Practice Management and Outcomes Research

VA Ann Arbor Healthcare System

P.O. Box 130170

Ann Arbor, MI 48113-0170

E-mail: Sonia.Duffy@med.va.gov 
This article has been cited by:

1. Sonia A. Duffy, Laurel A. Copeland, Faith P. Hopp, Robert J. Zalenski . 2007. Diagnostic Classifications and Resource Utilization of Decedents Served by the Department of Veterans AffairsDiagnostic Classifications and Resource Utilization of Decedents Served by the Department of Veterans Affairs. Journal of Palliative Medicine 10:5, 1137-1145. [Abstract] [PDF] [PDF Plus] 